https://helda.helsinki.fi

Can green infrastructure help to conserve biodiversity?

Salomaa, Anna

2017-03

Salomaa , A , Paloniemi , R , Kotiaho , J S , Kettunen, M , Apostolopoulou , E \& Cent , J 2017 , ' Can green infrastructure help to conserve biodiversity? ' , Environment and Planning C: Politics and Space , vol. 35 , no. 2 , pp. 265-288 . https://doi.org/10.1177/0263774X16649363

http://hdl.handle.net/10138/198035

https://doi.org/10.1177/0263774X16649363

unspecified

acceptedVersion

Downloaded from Helda, University of Helsinki institutional repository.

This is an electronic reprint of the original article.

This reprint may differ from the original in pagination and typographic detail.

Please cite the original version. 
This is a pre-copy-editing, author-produced PDF of an article accepted following peer review for publication in Environment and Planning C: Politics and Space.

The definitive publisher-authenticated version is available online, DOI:

10.1177/0263774X16649363

\section{Can green infrastructure help to conserve biodiversity?}

Anna Salomaa ${ }^{12 *}$, Riikka Paloniemi², Janne S Kotiaho ${ }^{3}$, Marianne Kettunen ${ }^{4}$, Evangelia Apostolopoulou $^{5}$ and Joanna Cent ${ }^{6}$

${ }^{1}$ Department of Environmental Sciences, University of Helsinki, Finland

${ }^{2}$ Environmental Policy Centre, Finnish Environment Institute, Finland

${ }^{3}$ Department of Biological and Environmental Science, University of Jyväskylä, Finland

${ }^{4}$ Institute for European Environmental Policy, UK and Belgium

${ }^{5}$ Department of Geography, University of Cambridge, UK

${ }^{6}$ Institute of Environmental Sciences, Jagiellonian University, Poland

*Corresponding author anna.salomaa@helsinki.fi, +358 504480941

\section{Introduction}

A number of important global agreements have been made with the purpose of enhancing the conservation of biodiversity. Despite these agreements, degradation and decline of biodiversity still continues (Dirzo et al., 2014; Tittensor et al., 2014). The 
ongoing biodiversity decline is driven by pollution, invasive alien species, overexploitation of species, climate change (Butchart et al., 2010), and most importantly, increasingly fragmented landscape mosaics consisting of isolated and degraded habitats (Hanski, 2005). A cause that underlies all these drivers is intensive nature exploitation and land transformation to support current growth and consumption patterns. Biodiversity loss has already been estimated to have crossed the safe boundaries from a human perspective and its consequences for human development are accelerating (Rockström et al., 2009).

Green infrastructure (GI) is an approach that has been presented as having the potential to address the above challenges. The GI concept, as well as other closely related concepts, have been used mainly in the USA and the European Union (Benedict and McMahon, 2006; Horwood, 2011; Lennon, 2015a). Several alternative interpretations exist, because the concept and experiences from implementing it have their origins in different academic disciplines, such as nature conservation, urban and landscape planning and greenways development (Benedict and McMahon, 2006; Lennon, 2015b). Common to different definitions is the idea of managing land, planning natural areas to benefit people and supporting nature conservation (Benedict and McMahon, 2006; Lennon, 2015b) or, in other words, the idea of combining connectivity, multifunctionality and green spaces (Wright, 2011). GI could potentially direct 
environmentally harmful economic development away from biodiverse and ecologically important areas (Benedict and McMahon, 2002; Lennon and Scott 2014, Marcucci and Jordan, 2013). However, due to the complexity in the various, and sometimes contradicting, aims attached to the concept and the currently dominant environmental policy discourse on the need to contribute to economic development and growth, the implementation of GI in practice and its contribution to biodiversity conservation remain somewhat ambiguous (Benedict and McMahon, 2002; Lennon 2015b; Mell, 2013; Wright, 2011).

In the absence of clear theoretical or policy guidelines, practical applications have been relevant in the development of the GI concept: for example, the management of water and flood prevention have played an important role in the early evolution of the concept while more recently, climate change mitigation and adaptation has been added into GI's foreseen benefits (Matthews et al., 2015; Sussams et al., 2015). Importantly, the use of the term "infrastructure" in GI draws an analogy between areas of natural or seminatural ecosystems with manmade infrastructures, the basic physical elements and structures essential to society reflecting a systemic notion of interconnected elements rather than isolated spaces (Benedict and McMahon, 2002; Thomas and Littlewood, 2010). GI has been also used as synonym for or to include sustainable infrastructure (Carlet, 2015; Mell, 2013; Young et al., 2014), green investments (Baietti et al., 2012) 
or a focus on "greening" urban areas (e.g. Horwood, 2011; Matthews et al., 2015;

Tzoulas et al., 2007; Young et al., 2014). Developing GI in densely built areas (e.g. in central Europe) in parallel to the rise of smart growth thinking has resulted in emphasizing the benefits of GI for economic growth (Horwood, 2011; Thomas and Littlewood, 2010), human wellbeing and health (Tzoulas et al., 2007), and thus to a situation where the aim to conserve biodiversity is not always included in GI's definition or goals (Wright, 2011). In this paper, even though we acknowledge the importance of the breadth of GI's interpretations and applications in practice in shaping the concept, we focus on GI's deployment in the European Union (EU) context, which we describe next.

Green infrastructure has been recently presented as an essential element of the EU biodiversity policy as described in the latest EU biodiversity strategy 2011-2020 (EC, 2011). In a dedicated EU GI strategy, GI was defined as " $a$ strategically planned network of natural and semi-natural areas with other environmental features designed and managed to deliver a wide range of ecosystem services. It incorporates green spaces (or blue if aquatic ecosystems are concerned) and other physical features in terrestrial (including coastal) and marine areas. On land, GI is present in rural and urban settings" (EC, 2013a: 3). The European Commission stated its intention to support the implementation of GI by increasing access to funding, providing technical 
guidance and improving the knowledge base within the context of existing legislation and policy instruments (EC, 2013a).

In Europe, an important idea that preceded the GI, was the concept of ecological networks consisting of core areas, corridors, buzzer zones and restored areas (Benedict and McMahon, 2006; Mazza et al 2011; Nauman et al., 2011). Thus, the network of Natura 2000 sites forms the backbone of EU's GI (EC, 2013a; Maes et al., 2015; Mazza et al., 2011). Numerous GI projects have already been realized, but they have not necessarily been named as such (EC, 2013a, 2013b; EEA, 2011; Mazza et al., 2011; Nauman et al 2011). These have, for example, included nature conservation areas, landuse planning instruments or instruments to enhance the connectivity of existing areas. After the increase of the GI concept's political popularity, there has also been targeted methodological development for its mapping and implementation (e.g. Kopperoinen et al., 2014; Liquete et al., 2015; Maes et al., 2015; Snäll et al., 2016).

At the core of the EU GI strategy lie two concepts which are also defined in various ways: ecosystem services and ecological connectivity. The concept of ecosystem services has its roots in a critique of traditional economics, and reflects a very specific reframing of biodiversity conservation around the measurement of the economic values of nature (Apostolopoulou and Adams, 2015; Costanza et al., 1997; Dempsey and 
Robertson, 2012). Since the Millennium Ecosystem Assessment (2005), the most influential initiative to mainstream the ecosystem service concept, the classification has been revised to further emphasize the economic benefits of biodiversity (Kumar, 2010) and need to proceed to an accounting of ecosystem services (EEA, 2013). Despite the ongoing debates around the definitions and implications of the concept for conservation (Balvanera et al., 2014; Vira and Adams, 2009), ecosystem services have gained popularity and the concept has now become a key element of mainstream environmental policy (Redford and Adams, 2009).

Ecological connectivity has also been defined and measured in a variety of ways. Different understandings of connectivity have been divided into three major categories: species specific habitat connectivity, spatial structure of vegetation cover and connectivity of ecological processes (Lindenmayer and Fischer, 2006). Therefore, definitions of connectivity may include functional and structural aspects (e.g., Moilanen and Hanski, 2001; Taylor et al., 1993; Tischendorf and Fahrig, 2000). Functional connectivity mainly affects biodiversity by restricting or enabling species dispersal, and thus is a species specific attribute. Consequently, it is impossible to specifically determine functional connectivity across species. Structural connectivity refers to the physical organization of patches and it is often correlated with functional connectivity simply because smaller physical distances are easier for many species to disperse than 
greater distances. Nevertheless, from the perspective of maintaining viable populations and the conservation of biodiversity, it is the functional connectivity that really matters. In practice, however, the structural aspects are easier to comprehend, measure and map, for example from aerial photographs in spatial planning (see also Löfvenhaft et al., 2002).

Connectivity has been addressed in the Habitats Directive and Birds Directive, which form the foundations of the EU biodiversity policy. Compared to the earlier planning of ecological connections and networks, EU GI emphasized the capacity of green areas to provide services to humans and aimed to integrate service provision into spatial planning and land-use development (EC, 2013a). GI is promoted by the EU as a policy which can reduce biodiversity loss and contribute to adaptation to and mitigation of climate change's effects (EC, 2013a). Various EU documents on GI have also emphasized the role of GI in enabling growth, green businesses and investment, and the need to enhance biodiversity conservation and economic growth simultaneously (e.g. EC, 2012, 2013a). Indeed, in the recent EU communication on GI the conservation of biodiversity appears to be downgraded (EC, 2013a).

For the purposes of this study, we adopted a definition of GI based on earlier studies while also taking into consideration relevant EU documents that have played an 
important role in shaping the official EU GI strategy (EC, 2011; EEA, 2011; Mazza et al., 2011; Nauman et al., 2011). In particular, we define GI as "connected green and blue spaces that enable the functioning of ecological processes and produce ecosystem services". We chose to adopt this definition because GI was not yet defined or implemented at the European level or at national level (in Finland where we conducted our study) at the time we conducted our fieldwork (the relevant EU communication, EC, 2013a, that defined GI was published few months after we conducted our study). Moreover, although the concept had appeared in important Finnish policy documents (e.g., Finnish Government, 2012), it has not been implemented through a national policy. Our definition was general and did not emphasize the role of biodiversity conservation, urban areas or any other specific type of land use pattern. In our definition, any particular implementation aspect was not emphasized either, in order to encourage respondents to approach the concept based on their professional positions and perceptions rather than on a perspective fixed in advance. The main difference between the definition used in this research and that published by the EU (EC, 2013a) is the emphasis on strategic planning and on both natural and semi-natural areas in the latter.

So far, the concept of GI remains quite ambiguous and the ways it will be implemented in practice are still under discussion at EU, national and local levels. The academic 
literature critically evaluating the implications of GI in environmental policy (Lennon, $2015 b$ ) is also quite limited. In this paper, we aim to contribute in filling this lacuna by exploring the perceptions of Finnish professionals' on how GI should be implemented and on its capacity to contribute to the conservation of biodiversity as part of the already existing policy framework. In particular, we investigate their perceptions on: a) the development of GI, b) the extent to which the adoption of the GI concept is facilitating change in environmental policy, and c) the potential importance of current biodiversity policy instruments in promoting connectivity and their current performance in promoting connectivity in practice. Our research participants include researchers and practitioners in biodiversity conservation who have knowledge on various aspects relevant for GI implementation and who have been involved in the designation of relevant policies and implementation guidelines. Therefore, their opinions about GI can shape and be used to evaluate its role for biodiversity conservation. Following Lennon's observation (2015a) that the fluidity and flexibility of the GI concept is contributing to its political popularity, we investigate how ambiguity may affect GI's implementation in practice. Several policy instruments that represent different aspects of GI already exist (EC, 2013b), and thus we analyze GI as a part of the existing and developing policy framework. 
In what follows we first describe our empirical design and data analysis methods and we proceed with presenting the results of our empirical research. Then we discuss our results by drawing on the relevant scientific literature and finally we present our conclusions on the potential of GI to promote biodiversity conservation in Europe.

\section{Materials and methods}

\section{Respondents}

We sent a questionnaire to 214 Finnish professionals during the period from November 2012 to January 2013. We selected professionals who, based on their position in their organizations, were expected to work on issues related to biodiversity conservation, ecological connectivity and development of GI policies. We selected natural and environmental social scientists from universities and research institutions, professionals working in the environmental and forestry administration, non-governmental organisations and nature-related private sector bodies. In addition to national level representatives, we selected regional environmental authority representatives from five Centers for Economic Development, Transport and Environment (ELY-Centres) and local representatives from 10 cities and municipalities (Figure 1). The selected cities represented the following ELY-Centers: Uusimaa in Helsinki, Southeast Finland in Kouvola, North Savo in Kuopio, Pirkanmaa in Tampere and North Ostrobothnia in Oulu. 
The questionnaire was administrated via a web service (Webropol) and a link was sent to the respondents by email. The questionnaire was in Finnish, and it was not mandatory to answer all questions. Altogether 47 professionals responded to the questionnaire. The background of the respondents is described in Appendix 1. People who had a background in forestry, biology and interdisciplinary sciences were over-represented reflecting the disciplines that have had major contribution to landscape level conservation in Finland. People working only at the local level were under-represented, indicating the fact that local level GI implementation was not topical when we sent the survey. Our aim was not to gather a representative sample of all professionals in the country, but rather to focus on those who have a say in designing and implementing in practice biodiversity and GI policies. Prior to our study, $87 \%$ of the respondents had already participated in a project considering ecological connectivity. In addition, the questionnaire included a number of questions on detailed aspects of ecological connectivity; and we got feedback from several potential respondents that the questionnaire was difficult to fill in without expertise in that field. 


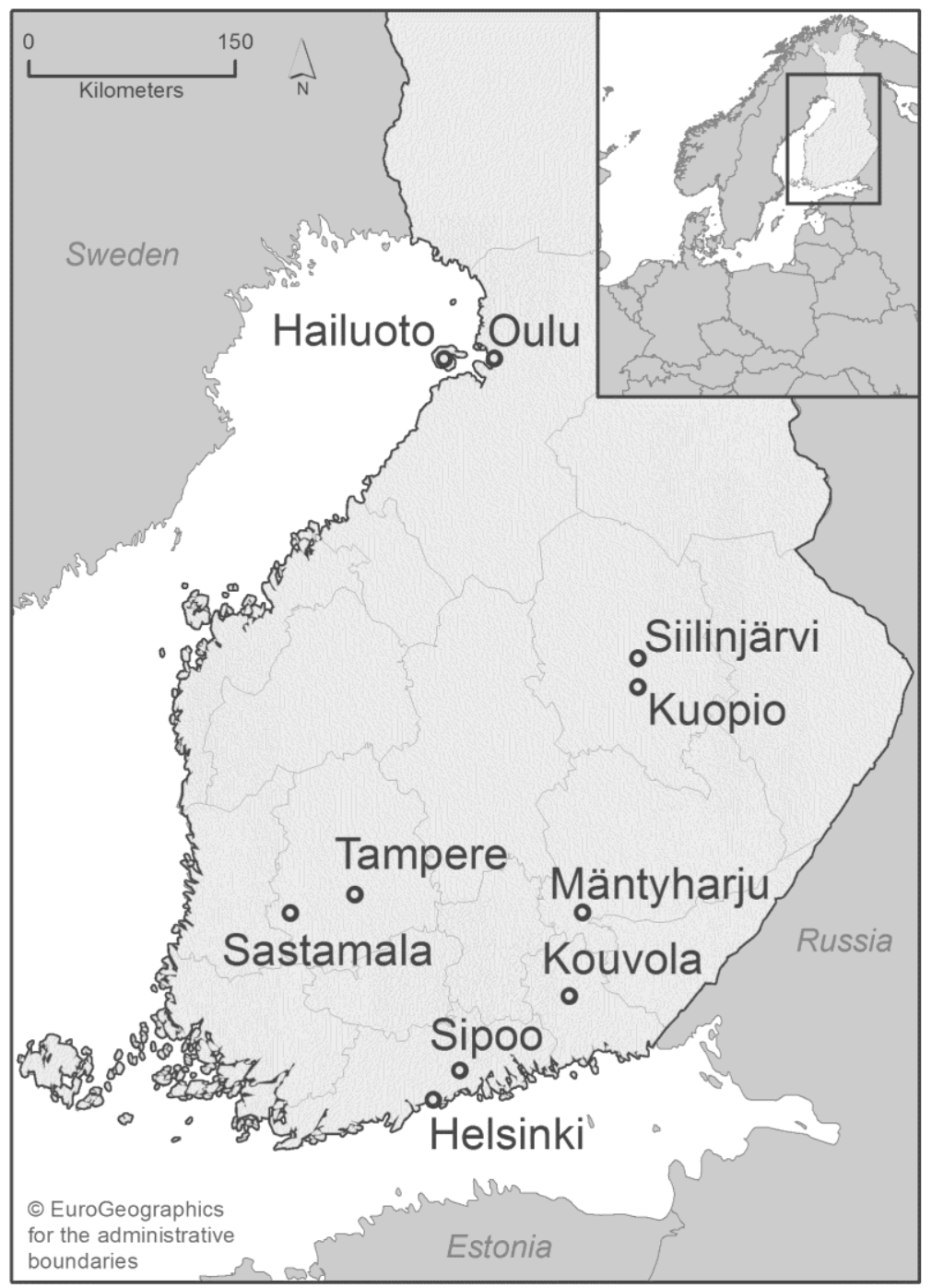

Figure 1. Surveyed regions, cities and municipalities in Finland.

Questionnaire and analysis methods - development of green infrastructure and policy changes 
In the questionnaire we first presented questions on policy instruments promoting ecological connectivity and second questions on GI, to study the current policy context before turning the focus of respondents to future policy development and implementation. We presented the definition of GI concept just before asking the questions on GI. Here, we begin with the results on GI and then we continue with the results on existing policy instruments.

In order to determine how the respondents perceive GI should be developed, we presented several statements in the questionnaire (Table 1). We drafted statements on design so that they had either a biodiversity conservation theme directly or through other themes that had been emphasized in earlier GI definitions and could be important for potential implementation methods. Different themes in statements were structural connectivity (statements $1,2,3)$, ecosystem functions $(4,5,8)$, ecosystem services $(5,6$, $7)$ and direct biodiversity conservation $(8,9,10)$. We also analyzed to what extent the adoption of the concept of GI is perceived to facilitate a change in existing environmental policy (11-18). These themes were not disclosed to the respondents. Respondents evaluated the GI statements using a Likert scale (1 completely disagree -5 completely agree). Hierarchical cluster analysis was used to determine the entities which the pre-given statements formed (Appendix 2). The GI definition we adopted 
affected our interpretation of the clusters. All statistical tests were performed in IBM SPSS Statistics 20 or 21.

To encourage respondents to list their opinions regarding how GI could facilitate a change in environmental policy, we also used an open question. The open question was analyzed qualitatively using content analysis: different propositions were combined to form answer categories inductively. The same proposition could fall into several categories. Finally, we judged categories based on whether they promote or challenge biodiversity conservation.

Questionnaire and analysis methods - current policy instruments

In order to investigate the usefulness of existing policy instruments in promoting biodiversity conservation through connectivity (Mazza et al., 2011; Nauman et al., 2011), we presented a list of nature conservation policy instruments with two questions:

a) How potentially important is the instrument for promoting connectivity and b) How well does the instrument promote connectivity in practice as an element of the current policy mix. In the policy instrument list, several instruments represented different aspects of GI that, based on the GI definition we adopted in this study, where most important components of GI (core areas, corridors and buffer zones). Because land-use change is considered as one of the main drivers for developing GI policies, benefiting 
current land-use planning instruments represents another approach of implementing GI. We formed the instrument groups to include the following policy instruments: 1) “Connectivity Enhancing Instruments" (buffer zones and corridors), 2) "Core Area Instruments" (different types of protected areas) and 3) "Land-Use Planning Instruments" (Appendix 3; Table 3). We only included instruments that operate on a landscape level and did not include minor elements, such as underpasses or green bridges.

The respondents evaluated the instruments using a 5-point interval scale (a. How potentially important is the instrument for promoting connectivity: 1 unimportant; 2 of little importance; 3 moderately important; 4 quite important; 5 very important, b. How well does the instrument promote connectivity in practice as an element of the current policy mix: 1 not at all; 2 a little; 3 moderately; 4 quite a lot; 5 a lot). It was also possible to answer "I do not know" or "Instrument not in use", though these answers were not included in the statistical analyses. Statistical analyses were conducted only on respondents that had evaluated all instruments within each instrument group.

We calculated means for instrument groups and instruments, as well as standard deviations for instrument groups and instruments. It should be noted that since several policy instruments are to some extent overlapping (e.g. national parks and Natura 2000 
sites) the instrument groups could have been formed based on other criteria for different research aims. We also used Cronbach's alpha to estimate the internal consistency of the instrument groups (Cronbach, 1951).

The analysis of the capacity of policy instruments to promote biodiversity conservation through connectivity was divided into two parts. First, we assessed professionals' perceptions of the potential of the instruments to promote connectivity and of how well this potential is currently realized in practice within selected policy instrument groups. This analysis was carried out using repeated-measures analysis of variance (ANOVA), with a general linear model procedure and different instruments as the between-subjects factor. The repeated-measures general linear model procedure provides analysis of variance when measurements were made several times on each subject. We considered instruments as subjects and the respondent's evaluations of potential and currently realized performance as the repeated measurement. Appropriate post-hoc test, Fisher's Least Significant Difference (LSD), was used for pairwise comparisons. We used repeated-measures ANOVA as a pre-test for further calculations to determine if any of the instruments differed within an instrument group.

Second, we calculated average values for the potential and current performance of each of the three policy instrument groups. Average values were calculated for the 
respondents that have evaluated all instruments within potential or current performance of the instrument groups. We assessed whether the differences between potential and currently realized performance of the instrument groups differed. This analysis was also carried out by using repeated-measures analysis of variance (ANOVA) with a general linear model procedure. Given that the local detailed plans differed statistically significantly from two other instruments within the Land-Use Planning Instruments group (see results section), we excluded local detailed plans from the average for the Land-Use Planning Instrument group.

\section{Results}

Development of green infrastructure and policy changes

The cluster analysis of pre-given statements regarding the role of GI and policy change outcomes separated three clusters that did not directly reflect the themes around which the statements were initially drafted in the questionnaire. The first and second cluster separated biodiversity conservation and ecosystem services themes, whereas the third cluster focused on the implications of GI for environmental policy (Appendix 2).

Biodiversity conservation cluster included two statements on structural connectivity and ecosystem services cluster two statements on ecosystem functions but not the statement describing direct benefits as the most significant. Based on the mean values over the statements within clusters, it appears that the respondents consider both the 
conservation of biodiversity and the provision of ecosystem services as important objectives of GI (Table 1). The mean value for statements describing GI facilitating change in environmental policy was the lowest.

Table 1. Development of green infrastructure and policy change outcomes. Names of clusters separated in cluster analysis, pre-given statements, number of respondents evaluating the statement $(\mathrm{N})$, means of clusters and statements, standard deviation (SD) of clusters and statements and Cronbach's alpha $(\alpha)$ for clusters. Numbers describing the clusters are in bold. The scale for evaluating statements was 1 completely disagree 5 completely agree. $\mathrm{N}=43$.

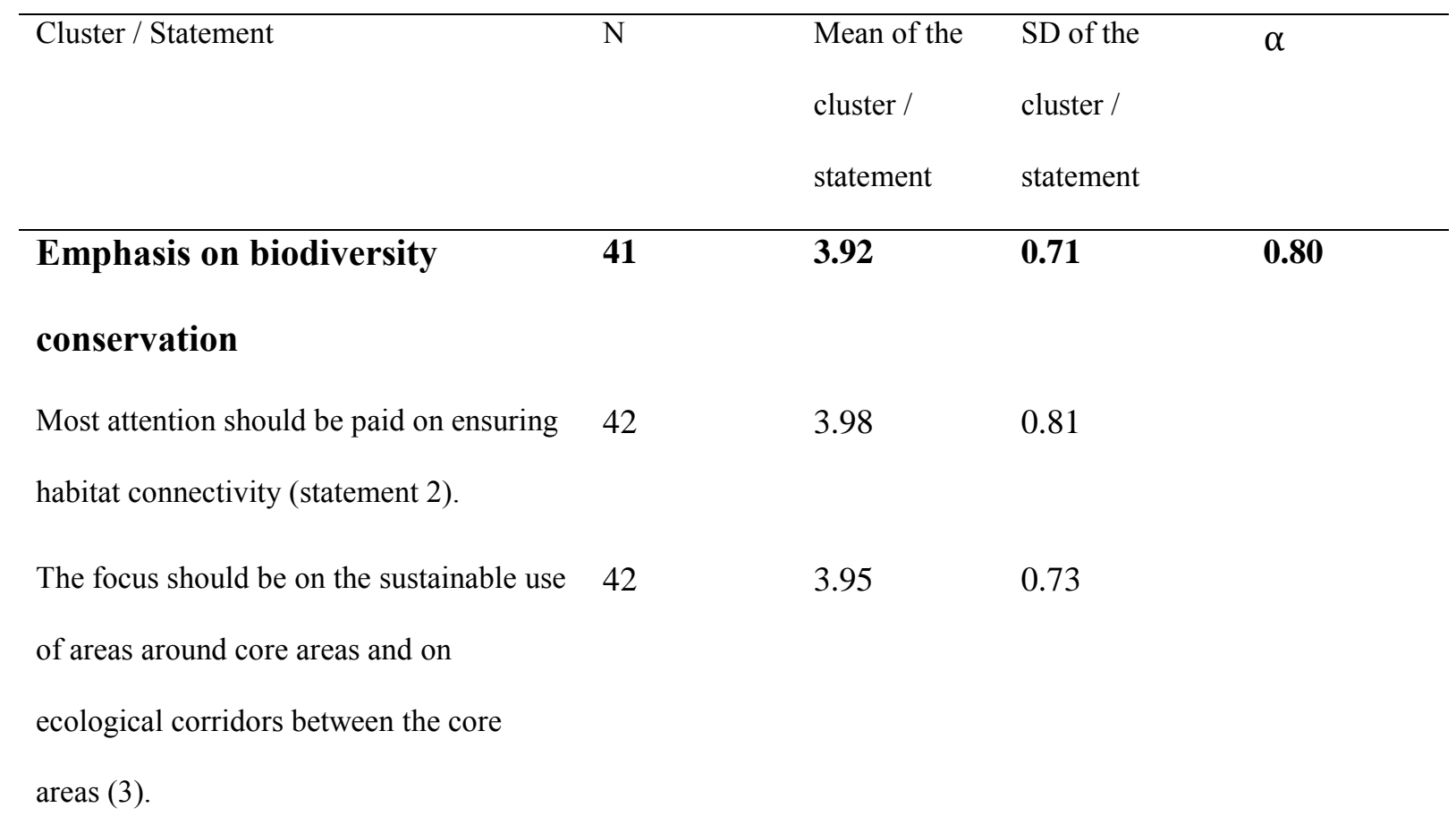


Primarily, the natural evolution and

42

3.86

1.00

distribution processes should be conserved

(8).

The conservation of biodiversity should be 41

3.95

1.24

the aim in itself, without the need to

consider the goods it provides to humans

(9).

Primarily the survival of biota, especially

42

3.90

0.91

rare species living in the area, should be

ensured (10).

\section{Emphasis on ecosystem services}

The focus should be on ensuring the

functioning of ecological processes, e.g.

photosynthesis and decomposition (4).

The most important are the production of

clean water and air and similar services

(5).

When implementing, primarily ecosystem

42

3.40

1.01

services should be considered (6).

\section{Green infrastructure facilitating 39}

3.25

0.76

0.92

\section{change in environmental policy}

The concept of green infrastructure will 
make environmental policy more holistic

(11).

The concept of green infrastructure will

introduce consideration of the

functionality of ecosystems to

environmental policy (12).

The concept of green infrastructure will

better integrate human and environmental

functions, especially in urban areas (13).

The green infrastructure approach will

41

3.49

0.84

help to conserve the biodiversity of

fragmented habitats (14).

The green infrastructure approach will

help to halt the loss of biodiversity (15).

The green infrastructure approach will

help to understand the economic value of the environment (16).

The green infrastructure approach will

help to remove environmentally harmful subsidies (17).

The green infrastructure will help to adapt

to and mitigate climate change (18). 
Respondents opinions, based on the open question regarding the changes that GI could facilitate in environmental policy, are summarized in Table 2. The respondents considered that GI could have some potential to enhance nature conservation indirectly. The most frequent answer category, Increased appreciation of nature values, included integrating biodiversity into different policy sectors in the future. Excerpts from this category are: "mainstreaming - spreading of thinking of biodiversity to all sectors of governance”, "green values will rise to social discussion and decision-making more effectively", and "the conservation of biodiversity becomes everyday practise". The category Better ecological understanding and environmental awareness included also better understanding of the functionality of biodiversity in the future. Excerpts from this category are: "better understanding of ecological connectivity" and "increase in nature and environmental awareness. Descriptive excerpts from the category More holistic consideration of environment and/or land-use planning are: "more consideration of spatial entities" and "holisticity". An excerpts illustrating the category More attention to green areas especially in the urban context are: "strengthening the simultaneous consideration of construction and green areas" and "will (hopefully) reduce one-sided maintenance of green areas that focus only on economic value and efficiency".

Table 2. Changes that respondents thought green infrastructure could bring to environmental policy. Answer categories are inductively created from the open 
question. Numbers of mentions are presented in parenthesis. The possible consequences are judged from a biodiversity conservation perspective. $\mathrm{N}=20$.

\begin{tabular}{ll}
\hline Answer categories & Possible consequences \\
\hline Increased appreciation of nature values (9) & Promote biodiversity \\
Better ecological understanding and environmental & conservation \\
awareness (8) & \\
More holistic consideration of the environment & \\
and/or land-use planning (8) & \\
More attention to green areas, especially in the & \\
urban context (5)
\end{tabular}

Seeing nature as services for humans (7)

Not clear link to biodiversity

Better recreation opportunities (1)

conservation

Comfortable living environment (1)

Innovative methods (1)

Concept too abstract for practical decision-making Challenge biodiversity

conservation

No change to current practices, due to the power of

the economic sector (1)

Nothing but more attention to construction of green

spaces by humans (1) 
Respondents thought that GI might increase Seeing nature as services for humans in environmental policy. This category included comments on better understanding the services ecosystems provide, and comments with a high emphasis on economic value. Excerpts from this category include: "the values and services produced by nature and ecosystems are recognized better, and these qualities are valued"; "will highlight even more economic values / direct benefits to humans" and "increasing economy- and anthropocentrism". The respondents' comments on services, however, were not linked to increased biodiversity conservation. There were also other opinions which did not have a clear link to biodiversity conservation. An excerpt from one such opinion is: "improvement of outdoor and recreation opportunities". Some respondents directly challenged the potential of the GI approach to conserve biodiversity. Excerpts from these include: "the concept is too abstract to have a real effect on practical decisionmaking", and "The thinking is not enough. There has to be also action. Unfortunately the economy dictates almost all actions and overrides green values. So probably there will be no change."

\section{Current policy instruments}

Respondents' opinions about the potential and current performance of policy instrument groups - Connectivity Enhancing Instruments, Core Area Instruments, and Land-Use 
Planning Instruments - in supporting biodiversity conservation through promoting connectivity are presented in Table 3. Potential performance had higher mean values than current performance in all instrument groups. Potential performance was evaluated to be highest in Connectivity Enhancing Instruments and Core Area Instruments. Current performance was evaluated as being the highest in Core Area Instruments.

Table 3. Policy instrument groups and their potential and currently realized performance in promoting connectivity. Names of instrument groups and instruments in each group, number of respondents $(\mathrm{N})$, mean for instrument groups and instruments, standard deviation for groups and instruments (SD), and Cronbach's alpha $(\alpha)$ for instrument groups. Numbers describing instrument groups are shown in bold.

\begin{tabular}{|c|c|c|}
\hline Instrument groups and & Potential & Current performance \\
\hline policy instruments & performance & \\
\hline
\end{tabular}

$\begin{array}{lllllllll}\text { Connectivity Enhancing } & 41 & 3.98 & 0.89 & 0.74 & 32 & 2.23 & 0.92 & 0.72\end{array}$

Instruments

$\begin{array}{lllllll}\text { Ecological corridors } & 41 & 4.07 & 0.96 & 32 & 2.41 & 1.04 \\ \text { Buffer zones around } & 41 & 3.88 & 1.03 & 32 & 2.06 & 1.05\end{array}$

conservation areas

$\begin{array}{lllllllllll}\text { Core Area Instruments } & & 37 & 3.95 & 0.63 & 0.78 & 28 & 2.96 & 0.82 & 0.85\end{array}$


Strict nature reserves

$\begin{array}{lll}37 & 3.62 \quad 1.32\end{array}$

$\begin{array}{lll}28 & 2.79 & 1.47\end{array}$

National parks

$\begin{array}{lll}37 & 3.95 & 0.97\end{array}$

$28 \quad 3.00$

1.15

Natura 2000 sites

$\begin{array}{lll}37 & 3.97 & 0.93\end{array}$

$\begin{array}{lll}28 & 3.21 & 0.92\end{array}$

Areas protected under

$\begin{array}{lll}37 & 4.24 & 0.72\end{array}$

$\begin{array}{lll}28 & 3.00 & 0.94\end{array}$

conservation programmes

and under the Act on the

Protection of Rapids

Permanent conservation of

$37 \quad 4.03$

0.73

$28 \quad 2.86$

1.04

private land as a part of The

Forest Biodiversity

Programme METSO

Conservation of state-

$\begin{array}{lll}37 \quad 3.89 & 1.02\end{array}$

$28 \quad 2.82$

1.12

owned land as a part of The

Forest Biodiversity

Programme METSO

Wilderness areas in Lapland

$\begin{array}{lll}37 & 3.95 & 0.88\end{array}$

$\begin{array}{lll}28 & 3.04 & 1.07\end{array}$

Land-Use Planning

$38 \quad 3.78$

0.930 .86

$32 \quad 2.59$

$0.75 \quad 0.79$

\section{Instruments}

$\begin{array}{lllllll}\text { National land-use objectives } & 38 & 3.63 & 1.10 & 32 & 2.44 & 0.76 \\ \text { Regional plans } & 38 & 3.82 & 1.04 & 32 & 2.69 & 0.97\end{array}$



Local master plans
$\begin{array}{lll}38 & 3.89 & 1.01\end{array}$
$\begin{array}{lll}32 & 2.66 & 0.94\end{array}$

(Local detailed plans, not

included in average of

instrument group)

In the analysis of the capacity of existing policy instruments to promote biodiversity conservation through connectivity, there was no mean difference among Connectivity Enhancing Instruments in how they promote connectivity (ANOVA, GLM, $\mathrm{F}_{1,67}=3.21$ $\mathrm{P}=0.078$ ). However, the potential of Connectivity Enhancing Instruments was perceived to be higher than what has been achieved with the current implementation (ANOVA, GLM, $\mathrm{F}_{1,67}=138.18 \mathrm{P}<0.001$ ), and the difference was constant across the instruments (i.e. no difference in the difference among the instruments) (ANOVA, GLM, $\left.\mathrm{F}_{1,67}=0.03, \mathrm{P}=0.865\right)$.

Similarly, there was no mean difference among Core Area Instruments in how the instruments promote connectivity (ANOVA, GLM, F6, $245=0.71, \mathrm{P}=0.642$ ). However, the potential of Core Area Instruments was perceived to be higher than what has been achieved with the current implementation (ANOVA, GLM, $\mathrm{F}_{1,245}=249.72, \mathrm{P}<0.001$ ) and the difference was constant across the instruments (ANOVA, GLM, F $6,245=1.15, \mathrm{P}$ $=0.332)$. 
There was a difference among Land-Use Planning Instruments in how the instruments promote connectivity (ANOVA, GLM, $\mathrm{F}_{3,139}=3.27 \mathrm{P}=0.002$ ). LSD post hoc analysis showed that regional plans and master plans were perceived to promote connectivity better than local detailed plans (for both mean difference $>0.48, \mathrm{P}<0.018$ ). The potential of Land-Use Planning Instruments was perceived to be higher than what has been achieved with the current implementation (ANOVA, GLM, $\mathrm{F}_{1,139}=141.10, \mathrm{P}<$ 0.001) and the difference was constant across the instruments (ANOVA, GLM, F $3,139=$ $0.22, \mathrm{P}=0.881)$.

When instruments were combined to groups, there was no mean difference among instrument groups in how the instruments promote connectivity (ANOVA, GLM, F2, 89 $=2.24 \mathrm{P}=0.113$ ). However, the potential of instrument groups was perceived to be higher than what has been achieved with the current implementation (ANOVA, GLM, $\left.\mathrm{F}_{1,89}=161.34, \mathrm{P}<0.001\right)$. Notably, there was a difference in the potential and currently realized performance among the instrument groups (ANOVA, GLM, $\mathrm{F}_{2,89}=4.55, \mathrm{P}=$ 0.013). LSD post hoc analysis showed that Connectivity Enhancing Instruments had significantly wider gap between current and potential performance than Core Areas Instruments, which had the smallest gap (mean difference $=0.38, \mathrm{P}=0.039$ ). 


\section{Discussion - Possibilities and challenges of green infrastructure to contribute to biodiversity conservation}

\section{Development of the green infrastructure}

When analyzing the perceptions of Finnish professionals on the development of the GI, we found three possible emphases, namely biodiversity conservation, ecosystem services, and potential changes in existing policy. Even though biodiversity conservation and ecosystem services were both seen as important aspects in the design of GI, the importance of developing GI in a way that emphasizes biodiversity conservation was slightly but consistently higher than that of emphasizing ecosystem services. This is quite of importance if we take into consideration that we did not mention biodiversity conservation in our definition of GI. Interestingly, the perspective of emphasizing ecosystem services excluded the statement underlining direct benefits produced by green and blue spaces when implementing GI. Thus, it appears that focusing only on direct ecosystem benefits is not considered to be the same as the overall idea of ecosystem services.

Our results indicate that the respondents viewed biodiversity conservation to differ from ecosystem services. Indeed, even though the ecosystem services concept can support the conservation of biodiversity (Schröter et al., 2014; Turner et al., 2007), it does not render the focus on biodiversity unnecessary (Schröter et al., 2014). Our results indicate 
that ecosystem services play a dual role in GI policy: ecosystem services are a central element of the definition but during implementation, the focus should not lie (solely) on ecosystem services. This observation adds to the ongoing debates about the way the ecosystem services concept reframes conservation, and its relation to the commodification of ecosystems (Gómez-Baggethun and Ruiz Pérez, 2011; Redford and Adams, 2009; Schröter et al., 2014). Focusing only on short term maximization of ecosystem services may have severe negative effects on biodiversity and human wellbeing in the long run. The benefits of the approach for biodiversity conservation will be undermined if a number of ecosystem services that have high synergies with biodiversity conservation (e.g. regulating services) are ignored. If conservation objectives carry trade-offs with objectives related to the maintenance and utilisation of (some) ecosystem services that are valued more than conservation, the concept of ecosystem services becomes nothing more than a synonym for the utilization of natural resources. It is also possible that ecosystem services may encourage the conservation of nature only when it is seen as beneficial and economically profitable, i.e. ignoring the intrinsic value of biodiversity (McCauley, 2006). Overall, it is not certain whether focusing on the maintenance of ecosystem services can also - and especially on its own and directly - guarantee the attainment of biodiversity conservation objectives (Bennett et al., 2009; Gómez-Baggethun and Ruiz Pérez, 2011; Redford and Adams, 2009). This 
adds to the risk that a GI policy focusing solely on ecosystem services would not be beneficial to biodiversity conservation.

\section{Potential policy changes}

The respondents presented rather positive but nonetheless ambivalent images regarding GI's potential to facilitate a change in existing environmental policy. Different potential changes were not associated with specific ways of designing GI, and the agreement with GI facilitating change was not strong. On the one hand, the respondents listed only few direct challenges for biodiversity conservation. On the other hand, in the open question, only one respondent suggested that the GI approach would directly benefit the conservation of biodiversity. Instead the comments given described the potential interaction and dynamics that the GI approach could bring to current environmental policy in general. Our results reflect that GI has not yet been systemically implemented in Finland and the extent or direction of change is not yet clear. Ambivalent results may also reflect the anticipated simultaneous shift to 'soft governance' in spatial planning (Thomas and Littlewood, 2010) or the assumption that the continuation of current sectoral governance structures does not fully endorse GI (Sussams et al., 2015).

Some respondents suggested indirect effects that could be beneficial to biodiversity conservation. They believed that GI could change the current consideration of 
environmental and/or land-use planning in favour of more holistic approaches. The latter is a perspective that has been also emphasized in the literature (Lennon and Scott, 2014; Marcucci and Jordan, 2013). If appropriately interpreted and implemented, GI could potentially contribute to addressing interactions and linkages between different scales relevant to biodiversity conservation within landscapes (Kettunen et al., 2014). According to the respondents, the use of the GI concept may increase the appreciation, understanding and integration of the multiple values of nature in environmental governance. Such wider policy impacts have also been mentioned in the rapidly increasing research on ecosystem services (e.g. Niemelä et al., 2010; Schröter et al., 2014).

Our results also indicate that seeing nature as a provider of services (e.g. Dempsey and Robertson, 2012) is perceived as being an integral part of the GI concept and its implementation in practice, manifesting the strong policy emphasis of the last decade on ecosystem services and utilitarian framings of nature's values (see also Lennon, 2015b). Crucially, in the EU GI strategy it is explicitly stated that ecosystem services should be "correctly valued and then priced if appropriate, to promote GI solutions in spatial planning and decision-making processes in relation to infrastructure" (EC, 2013a:8). An emphasis on ecosystem services and especially on their monetary valuation suggests that nature and green spaces must be actively managed and measured as economic 
assets by quantifying the economic benefits and the ability of GI functions to secure investments (Thomas and Littlewood, 2010; Wright 2011). Thus, a key aspect of GI is to support human welfare, and by implication to promote development and growth by attracting actors pursuing entrepreneurialism and place competitiveness agendas (Thomas and Littlewood 2010). Indeed, Garmendia et al. (in press) state that current initiatives to enhance GI in the EU, the US and globally prioritize support for economic growth over the need to conserve biodiversity and natural ecosystems.

Moreover, some respondents seemed to associate GI with urban areas and not with large-scale core areas and their connectivity. The expansion of cities and interrelatedness of GI with human health highlights the role of biodiverse areas near urbanised places (Hanski et al., 2012; Niemelä et al., 2010; Tzoulas et al., 2007). Understanding GI as a concept mainly concerning urban areas is also widely present in the GI literature (e.g. Horwood, 2011; Matthews et al., 2015; Young et al., 2014) and possibly also in the EU context.

We have to point out that most of the respondents had been involved in projects and/or research that could be described as related to GI. In future, certain actor groups who were under-represented in the sample, such as local level practitioners or people whose background is in agriculture and geography, will take more part in the implementation 
of GI in practice and their opinions will become relevant as well. Because of small sample size, it was not possible to compare the perceptions of different respondent groups. This limitation of the study should be addressed in future research paying attention to the fact that different groups may have different power to influence the implementation of GI. As GI as a concept was probably new to many respondents, it is understandable that perceptions on its future implications were not fully consistent and without inner contradictions.

Role of current policy instruments in promoting connectivity

To determine the role of already existing green infrastructure policy instruments in enhancing biodiversity conservation, we paid special attention to their ability to promote connectivity. Overall, the professionals perceived that the potential of policy instruments to promote connectivity is quite high, and higher than what has been achieved with their current implementation. Among the policy instrument groups, the greatest gap between potential and current implementation was in Connectivity Enhancing Instruments (ecological corridors and buffer zones), indicating they have the greatest potential for improvement.

However, on the basis of our results, the core nature conservation areas (such as protected areas) are of particular importance for biodiversity conservation with current 
implementation. This highlights the importance of enhancing the current backbone of the EU GI, comprising large conservation areas, especially the Natura 2000 areas (EC, 2013a; Maes et al., 2015; Mazza et al., 2011). Rybicki and Hanski (2013) have suggested that conservation should focus on clustering habitat fragments. But in a resource limited world, clustering, or enhancing connectivity, would mean that we simultaneously make a decision not to conserve those areas that are not connected (Kotiaho and Halme, 2014). Although the Land-Use Planning Instruments had moderate to quite high potential to promote connectivity, their potential was nevertheless perceived to be the smallest among the GI policy instruments. Implementation of GI with land-use planning instruments requires strengthening the role of ecology in landuse planning systems (Cowell and Lennon, 2014; Kambites and Owen, 2006; Lennon and Scott, 2014; Marcucci and Jordan, 2013). When developing GI with the target of conserving biodiversity, the emphasis should be placed on core areas and on improving the implementation of existing policy instruments that connect conservation areas in the wider landscape.

However, despite the European Commission's willingness to integrate GI in different policy sectors and strengthen the existing knowledge base, it is not so far clear how GI will be implemented in the EU member countries, including Finland. As discussed above, the ecosystem services approach will be at the core of GI, following the 
definition of GI in the EU strategy (EC, 2013a). It seems likely that the EU-wide GI framework will be implemented as series of different individual initiatives and projects, building on already existing structures (e.g. the Natura 2000 network) and with a possible future focus on the urban context (EC, 2013a; European Parliament, 2013).

\section{Gaps between science and implementation in practice}

The ambiguity of concepts with strong political background and implications, like GI, may help to create political momentum (Lennon, 2015a). GI has gained acceptance despite of, or because of, its broad definition and without dedicated (scientific) methods (Cowell and Lennon, 2014; EEA, 2011; Lennon, 2015a; Mazza et al., 2011; Nauman et al., 2011). Our results demonstrate that this broad definition of the concept creates obstacles for the practical implementation of GI (Sussams et al., 2015).

In our study professionals evaluated that there is a gap between potential and current implementation of existing nature conservation and land-use planning instruments which indicates that certain factors hinder the optimal performance of these instruments. The perceived gap may reflect a limited integration of nature conservation to other policy sectors (EEA, 2011) and not only weak performance of the instruments itself. Sectoral governance of different elements of GI is not efficient (Mazza et al., 2011; Nauman et al., 2011) and may leave more room for contradicting interpretations of local 
level practitioners (Lennon, 2015b). However, our study does not explicitly address the factors limiting optimal performance.

The professionals expressed different understandings of the usefulness of GI for biodiversity conservation, including different general preconceptions regarding how to achieve nature conservation targets (see also Apostolopoulou and Paloniemi, 2012). Different scientific fields understand GI differently and the practitioners implementing policies may not be aware of the theoretical heritage of the concept. Different understandings challenge policy makers and practitioners to open the different interpretations of the concept, in order to unravel both conflicts and synergies between different groups and to facilitate better cooperation and dialogue between science and practice (Lennon, 2015b; Wright, 2011). Anyhow, defining GI policies and implementing them in practice are social processes where actors can make a difference both individually and collectively (Cowell and Lennon, 2014; Lennon 2015a).

Ambiguities and complexities may be hidden behind scientific methods assumed to be objective (Lennon, 2015b), such as those linked to the concept of ecosystem services, which is as a special way of tailoring ecological knowledge to policy makers (Jordan and Russel, 2014). Measuring ecosystem services often involve valuation, e.g. measuring their perceived usefulness, the use of land cover as a proxy or monetary 
valuation. Existing methods mainly allow the monitoring and assessment of the most tangible services, leading to ecosystem services being primarily approached as provisioning services (Primmer and Furman, 2012). Also common methods used in biodiversity conservation contain elements connected to values, e.g. modelling requires expert opinion, and species inventories decisions on which species to study. GI methods can in some cases combine several approaches, e.g. expert knowledge may be combined with GIS to frame areas based on ecosystem services provision potential (Kopperoinen et al., 2014) or spatial conservation priorization can account for ecosystem services and biodiversity features (Snäll et al., 2016). GI mapping and design require high level of expertise and face several challenges, e.g. data requirements, weighting synergies and trade-offs of different components (Marcucci and Jordan, 2013; Snäll et al., 2016). This is not to say that best knowledge cannot be acquired, but that using knowledge for policy purposes can never be entirely objective since it is a social and political process.

Proponents of ecosystem services argue that the more informed policy is on impacts on ecosystem services and benefits to people, more effectively it can conserve nature, but empirical studies do not confirm this unequivocally (Cowell and Lennon, 2014; Jordan and Russel, 2014). Weak use of ecosystem services knowledge in practice is in concordance with other studies on knowledge use (Jordan and Russel, 2014). Putting emphasis on the conservation of ecosystem services rather than protection of 
biodiversity carries the risk of undermining biodiversity conservation efforts. This is because emphasis on ecosystem services can be narrowly - and incorrectly - interpreted as a need for monetary justifications for conservation, even leading to the commercialization and privatization of non-human nature and the deregulation of environmental legislation (Apostolopoulou and Adams, 2015; Horwood, 2011; Thomas and Littlewood, 2010). The scale of investments to implement GI at EU level, is available only through funding instruments which use requires demonstrating creation of jobs and economic growth (Maes et al., 2015). It must be ensured that the scientific basis of new concepts, such as biodiversity being prerequisite for ecosystem services production, is not forgotten along the way (see also Murcia et al., 2014). When promoting win-win solutions is the key aim of policies, as in the case of the EU biodiversity policy and GI, this can risk leaving the different inevitable trade-offs and conflicts unaddressed.

\section{Conclusion}

Our empirical research has the potential to advance existing theoretical discussions on the implications of green infrastructure for biodiversity conservation. Our results show that the contribution of a dedicated EU policy for GI to the conservation of biodiversity is dependent on how GI will be implemented in practice and that the existing conceptual ambiguity may challenge GI's potential benefits to biodiversity. This is partly because 
of the key role ecosystem services play so far in defining and implementing the concept and the challenges of realization of the full potential of already existing policy instruments. Even though we found that launching the new concept could possibly improve environmental policy to be more integrative, and thus indirectly more beneficial to nature conservation, we also found that biodiversity conservation should receive a more explicitly defined role in the EU GI policy and its implementation than it currently has. A need to improve the implementation of existing biodiversity policy instruments is as an integral part of developing a GI policy. Despite the promises of the GI concept, its current definition and deployment in the EU context raises merited concerns regarding its ability to contribute to biodiversity conservation. These concerns need to be addressed before the concept can be effectively used to deliver biodiversity benefits in the EU.

\section{Acknowledgements}

We warmly thank Janne Hukkinen for his support, Stephen Venn for language editing Eduardo Olazabal for preparing the map of the surveyed area. This research was part of the SCALES project (Securing the Conservation of Biodiversity Across Administrative Levels and Spatial, Ecological and Temporal Scales). We thank our SCALES collaborators. 


\section{Funding}

The SCALES project is funded by the European Commission (FP7 grant 226 852).

Funding for AS came also from the Doctoral programme in interdisciplinary

environmental sciences; Helsingin yliopiston alumni ry Ympäristön ystävät;

Hämäläisten ylioppilassäätiö and Maa- ja vesitekniikan tuki ry. EA was supported by a Marie Curie Intra-European Fellowship (PIEF-GA-2013-622631) within the 7th

European Community Framework Programme (Conservation and Ecosystem Services in the New Biodiversity Economy-CESINE).

\section{References}

Apostolopoulou E and Adams WM (2015) Neoliberal capitalism and conservation in the postcrisis era: the dialects of "green" and "un-green" grabbing in Greece and UK. Antipode 47(1): $15-35$.

Apostolopoulou E and Paloniemi R (2012) Frames of Scale Challenges in Finnish and Greek Biodiversity Conservation. Ecology \& Society 17(4): 451-484.

Baietti A, Shlyakhtenko A, La Rocca R and Patel UD (2012) World Bank Studies: Green Infrastructure Finance: Leading Initiatives and Research. Washington DC: World Bank. 
Balvanera P, Siddique I, Dee L, Paquette A, Isbell F, Gonzales A, Byrnes J, O'Connor MI, Hungate BA and Griffin JN (2014) Linking Biodiversity and Ecosystem Services: Current Uncertainties and the Necessary Next Steps. BioScience 64(1): 49-57.

Benedict MA and McMahon ET (2002) Green Infrastructure: Smart Conservation for the 21st Century. Renewable Resources Journal 20(3): 12-17.

Benedict MA and McMahon ET (2006) Green Infrastructure: Linking Landscapes and Communities. Washington DC: Island Press.

Bennett EM, Peterson GD and Gordon LJ (2009) Understanding relationships among multiple ecosystem services Ecology Letters 12(12): 1394-1404.

Butchart SHM, Walpole M, Collen B, van Strien A, Scharlemann JPW, Almond REA, Baillie JEM, Bomhard B, Brown C, Bruno J, Carpenter KE, Carr GM, Chanson J, Chenery AM, Csirke J, Davidson NC, Dentener F, Foster M, Galli A, Galloway JN, Genovesi P, Gregory R.D, Hockings M, Kapos V, Lamarque J-F, Leverington F, Loh J, McGeoch MA, McRae L, Minasyan A, Morcillo MH, Oldfield TEE, Pauly D, Quader S, Revenga C, Sauer JR, Skolnik B, Spear D, Stanwell-Smith D, Stuart SN, Symes A, Tierney M, Tyrrell TD, Vié J-C and Watson R (2010) Global Biodiversity: Indicators of Recent Declines. Science 328: 1164-1168. Carlet F (2015) Understanding attitudes toward adoption of green infrastructure: A case study of US municipal officials. Environmental Science \& Policy 51: 65-76. 
Costanza R, d'Arge R, de Groot R, Farber S, Grasso M, Hannon B, Limburg K, Naeem S, O’Neill RV, Paruelo J, Raskin RG, Sutton P and van den Belt M (1997) The value of the world's ecosystem services and natural capital. Nature 387: 253-260.

Cowell R and Lennon M (2014) The utilisation of environmental knowledge in land-use planning: drawing lessons for an ecosystem services approach. Environment and Planning $C$ : Government and Policy 32: 263-282.

Cronbach LJ (1951) Coefficient alpha and the internal structure of tests. Psychometrika 16(3): $297-334$.

Dempsey J and Robertson MM (2012) Ecosystem services: Tensions, impurities, and points of engagement within neoliberalism. Progress in Human Geography 36(6): 758-779.

Dirzo R, Young HS, Galetti M, Ceballos G, Isaac NJB and Collen B (2014) Defaunation in the Anthropocene. Science 345(6195) : 401-406.

EC (2011) Communication from the Commission to the European Parliament, the Council, the Economic and Social Committee and the Committee of the Regions. Our life insurance, our natural capital: an EU biodiversity strategy to 2020. COM(2011) 244 final, 3 May. Brussels: European Commission.

EC (2012) The multifunctionality of green infrastructure. Science for Environmental Policy. In depth report, European Commission DG Environment News Alert Service, March. 
EC (2013a) Communication from the Commission to the European Parliament, the Council, the European Economic and social committee and the Committee of the Regions. Green Infrastructure (GI) - Enhancing Europe's Natural Capital. COM(2013) 249 final, 6 May. Brussels: European Commission.

EC (2013b) Commission staff working document. Technical information on Green Infrastructure. Accompanying the document COM(2013) 249 final. SWD (2013) 155 final, 6 May. Brussels: European Commission.

EEA (2011) Green infrastructure and territorial cohesion. The concept of green infrastructure and its integration into policies using monitoring systems. Technical report No 18, European Environment Agency, Copenhagen. Available at: www.eea.europa.eu/publications/greeninfrastructure-and-territorial-cohesion (accessed 15 February 2016).

EEA (2013) CICES V4.3. European Environment Agency. Available at: http://cices.eu/ (accessed 24 February 2016).

European Parliament (2013) European Parliament resolution of 12 December 2013 on Green Infrastructure - Enhancing Europe's Natural Capital (2013/2663(RSP)

Finnish Government (2012) Government Resolution on the Strategy for the Conservation and Sustainable Use of Biodiversity in Finland for the years 2012-2020, 'Saving Nature for People' 20 December 
Gómez-Baggethun E and Ruiz Pérez M (2011) Economic valuation and the commodification of ecosystem services. Progress in Physical Geography 35(5): 613-628.

Hanski I (2005) Landscape fragmentation, biodiversity loss and the societal response. EMBO reports 6(5): 388-392.

Hanski I, von Hertzen L, Fyhrquist N, Koskinen K, Torppa K, Laatikainen T, Karisola P, Auvinen P, Paulin L, Mäkelä MJ, Vartiainen E, Kosunen TU, Alenius H and Haahtela T (2012) Environmental biodiversity, human microbiota, and allergy are interrelated. Proceedings of the National Academy of Sciences 109(21): 8334-8339.

Horwood K (2011) Green infrastructure: reconciling urban green space and regional economic development: lessons learnt from experience in England's north-west region, Local Environment: The International Journal of Justice and Sustainability 16(10) : 963-975.

Jordan A and Russel D (2014) Embedding the concept of ecosystem services? The utilisation of ecological knowledge in different policy venues. Environment and Planning C: Government and Policy 32: 192-207.

Kambites C and Owen S (2006) Renewed prospects for green infrastructure planning in the UK. Planning Practice \& Research 21(4): 483-496.

Kettunen M, Apostolopoulou E, Bormpoudakis D, Cent J, Letourneau A, Koivulehto M, Paloniemi R, Grodzińska-Jurczak M, Mathevet R, Scott A and Borgström S (2014) EU Green Infrastructure: Opportunities \& the Need for Addressing Scales. In: Henle K, Potts SG, Kunin 
WE., Matsinos Y, Similä J, Pantis JD, Grobelnik V, Lyubomir P, and Settle J (eds) Scaling in Ecology and Biodiversity Conservation. Sofia : Pensoft Publishers, pp.128-132.

Kopperoinen L, Itkonen P and Niemelä J (2014) Using expert knowledge in combining green infrastructure and ecosystem services in land use planning: an insight into a new place-based methodology. Landscape Ecology 29: 1361-1375.

Kotiaho J and Halme P (2014) Aggregating protected habitats embraces implicit habitat conservation triage. Proceedings of Peerage of Science 1: e5.

Kumar P (ed) (2010) The Economics of Ecosystems and Biodiversity: Ecological and Economic Foundations. London and Washington: Earthscan.

Lennon M (2015a) Explaining the currency of novel policy concepts: learning from green infrastructure planning. Environment and Planning C: Government and Policy 33: 1039-1057.

Lennon M (2015b) Green infrastructure and planning policy: a critical assessment. Local Environment: The International Journal of Justice and Sustainability 20(8): 957-980.

Lennon M and Scott M (2014) Delivering ecosystems services via spatial planning: reviewing the possibilities and implications of a green infrastructure approach. Town Planning Review 85(5): 563-587.

Lindenmayer DB and Fischer J (2006) Tackling the habitat fragmentation panchreston. Trends in Ecology \& Evolution 22(3): 127-132. 
Liquete C, Kleeschulte S, Dige G, Maes J, Grizzetti B, Olah B and Zulian G (2015) Mapping green infrastructure based on ecosystem services and ecological networks: A Pan-European case study. Environmental Science \& Policy 54: 268-280.

Löfvenhaft K, Björn C and Ihse M (2002) Biotope patterns in urban areas: a conceptual model integrating biodiversity issues in spatial planning. Landscape and Urban Planning 58: 223-240.

McCauley DJ (2006) Selling out on nature. Nature 443(7): 27-28.

Maes J, Barbosa A, Baranzelli C, Zulian G, Batista e Silva F, Vandecasteele I, Hiederer R, Liquete C, Paracchini LM, Mubareka S, Jacobs-Crisioni C, Castillo CP and Lavalle C (2015) More green infrastructure is required to maintain ecosystem services under current trends in land-use change in Europe. Landscape Ecology 30: 517-534.

Marcucci DJ and Jordan LM (2013) Benefits and Challenges of Linking Green Infrastructure and Highway Planning in the United States. Environmental Management 51:182-197.

Matthews T, Lo AY, Byrne JA (2015) Reconceptualizing green infrastructure for climate change adaptation: Barriers to adoption and drivers for uptake by spatial planners. Landscape and Urban Planning 138: 155-163.

Mazza L, Bennett G, De Nocker L, Gantioler S, Losarcos L, Margerison C, Kaphengst T, McConville A, Rayment M, ten Brink P, Tucker G and van Diggelen R (2011) Green Infrastructure Implementation and Efficiency. Final report for the European Commission, DG Environment, Institute for European Environmental Policy, Brussels and London, 22 December. 
Available at:

www.ieep.eu/assets/898/Green_Infrastructure_Implementation_and_Efficiency.pdf (accessed 12 February 2016).

Mell IC (2013) Can you tell a green field from a cold steel rail? Examining the "green" of Green Infrastructure development. Local Environment 18(2): 152-166.

Millennium Ecosystem Assessment (2005) Ecosystems and Human Well-being: Synthesis. Washington DC: Island Press.

Moilanen A and Hanski I (2001) On the use of connectivity measures in spatial ecology. Oikos 95(1): 147-151.

Murcia C, Aronson J, Kattan GH, Moreno-Mateos D, Dixon K and Simberloff D (2014) A critique of the 'novel ecosystem' concept. Trends in ecology \& evolution 29(10): 548-553.

Naumann S, McKenna D, Kaphengst T, Pieterse M and Rayment M (2011) Design, implementation and cost elements of Green Infrastructure projects. Final report to the European Commission DG Environment, Ecologic Institute and GHK Consulting, 16 December. Available at: http://ec.europa.eu/environment/enveco/biodiversity/pdf/GI_DICE_FinalReport.pdf (accessed 12 February 2016). 
Niemelä J, Saarela S-R, Söderman, Kopperoinen L, Yli-Pelkonen V, Väre S and Kotze DJ (2010) Using the ecosystem services approach for better planning and conservation of urban green spaces: A Finland case study. Biodiversity and Conservation 19: 3225-3243.

Primmer E and Furman E (2012) Operationalising ecosystem service approaches for governance: Do measuring, mapping and valuing integrate sector-specific knowledge systems? Ecosystem Services 1: 85-92.

Redford KH and Adams WM (2009) Payment for Ecosystem Services and the Challenge of Saving Nature. Conservation Biology 23(4): 785-787.

Rockström J, Steffen W, Noone K, Persson Å, Chapin FSIII, Lambin EF, Lenton TM, Scheffer M, Folke C, Schellnhuber HJ, Nykvist B, de Wit CA, Hughes T, van der Leeuw S, Rodhe H, Sörlin S, Snyder PK, Costanza R, Svedin U, Falkenmark M, Karlberg L, Corell RW, Fabry VJ, Hansen J, Walker B, Liverman D, Richardson K, Crutzen P and Foley JA (2009) A safe operating space for humanity. Nature 461: 472-475.

Rybicki J and Hanski I (2013) Species-area relationships and extinctions caused by habitat loss and fragmentation. Ecology Letters 16: 27-38.

Schröter M, van der Zanden EH, van Oudenhoven APE, Remme1 RP, Serna-Chavez HM, de Groot RS and Opdam P (2014) Ecosystem services as a contested concept: a synthesis of critique and counter-arguments. Conservation Letters 7(6): 514-523. 
Snäll T, Lehtomäki J, Arponen A, Elith J and Moilanen A (2016) Green Infrastructure Design Based on Spatial Conservation Prioritization and Modeling of Biodiversity Features and Ecosystem Services. Environmental Management 57(2): 251-256.

Sussams LW, Sheate WR and Eales RP (2015) Green infrastructure as a climate change adaptation policy intervention: Muddying the waters or clearing a path to a more secure future? Journal of Environmental Management 147: 184-193.

Taylor PD, Fahrig L, Henein K and Merriam G (1993) Connectivity is a vital element of landscape structure. Oikos 68(3): 571-573.

Thomas K and Littlewood S (2010) From green belts to green infrastructure? The evolution of a new concept in the emerging soft governance of spatial strategies. Planning, Practice \& Research 25(2): 203-222.

Tischendorf L and Fahrig L (2000) On the usage and measurement of landscape connectivity. Oikos 90: 7-19.

Tittensor DP, Walpole M, Hill SLL, Boyce DG, Britten GL, Burgess ND, Butchart SHM, Leadley PW, Regan EC, Alkemade R, Baumung R, Bellard C, Bouwman L, Bowles-Newark NJ, Chenery AM, Cheung WWL, Christensen V, Cooper HD, Crowther AR, Dixon MJR, Galli A, Gaveau V, Gregory RD, Gutierrez NL, Hirsch TL, Höft R, Januchowski-Hartley SR, Karmann M, Krug CB, Leverington FJ, Loh J, Lojenga RK, Malsch K, Marques A, Morgan DHW, Mumby PJ, Newbold T, Noonan-Mooney K, Pagad SN, Parks BC, Pereira HM, Robertson T, Rondinini C, Santini L, Scharlemann JPW, Schindler S, Sumaila U.R., Teh LSL, 
van Kolck J, Visconti P and Ye Y (2014) A mid-term analysis of progress toward international biodiversity targets. Science 346: 241-244.

Turner WR, Brandon K, Brooks TM., Costanza R, da Fonseca GAB and Portela R (2007)

Global Conservation of Biodiversity and Ecosystem Services. BioScience 57(10): 868-873.

Tzoulas K, Korpela K, Venn S, Yli-Pelkonen V, Kaźmierczak A, Niemelä J and James P (2007) Promoting ecosystem and human health in urban areas using Green Infrastructure: A literature review. Landscape and Urban Planning 3: 167-178.

Vira B and Adams WM (2009) Ecosystem services and conservation strategy: beware the silver bullet. Conservation Letters 2(4): 158-162.

Wright H (2011) Understanding green infrastructure: the development of a contested concept in England. Local Environment 16(10): 1003-1019.

Young R, Zanders J, Lieberknecht K and Fassman-Beck E (2014) A comprehensive typology for mainstreaming urban green infrastructure. Journal of Hydrology 519: 2571-2583.

Appendix 1. Background information on the respondents.

\begin{tabular}{lll}
\hline Educational & $\mathrm{N}=47$ & $2 \%$ Vocational school \\
background & & $15 \%$ Bachelor's degree
\end{tabular}


$55 \%$ Master's degree

$19 \% \mathrm{PhD}$

$2 \%$ Post-doctoral researcher

6\% Professor

\begin{tabular}{lll}
\hline Institutions $\quad \mathrm{N}=47 \quad 21 \%$ Environmental authority
\end{tabular}

$17 \%$ Scientific institution

$15 \% \mathrm{NGO}$

$13 \%$ Private sector

9\% Local administration

$6 \%$ Forestry authority

19\% Other (incl. certain authorities)

Administrative $\mathrm{N}=47 \quad 13 \%$ Local

levels

$34 \%$ Regional

$21 \%$ National 
$4 \% \mathrm{EU}$ or / and international

26\% Multiple levels

$2 \%$ Not specified

\begin{tabular}{lll}
\hline Scientific & $\mathrm{N}=47$ & $30 \%$ Forestry
\end{tabular}

discipline

$23 \%$ Conservation biology \& nature conservation

17\% Ecology \& biology

$17 \%$ Interdisciplinary

4\% Agriculture

$2 \%$ Genetics

2\% Hydrology \& limnology

$2 \%$ IT

2\% Environmental sciences

\begin{tabular}{ll}
\hline $\begin{array}{l}\text { Participation } \\
\text { in project in }\end{array}$ & $\begin{array}{l}\text { 33\% Both in practical project / policy process and research } \\
\text { project }\end{array}$ \\
which the & $50 \%$ Practical project / policy process \\
aspect of &
\end{tabular}




\begin{tabular}{l}
\hline ecological \\
connectivity \\
was taken into \\
account
\end{tabular}

\section{Appendix 2.}

The Euclidean distance was used as a metric because the variables were on a relative scale, and complete linkage (farthest neighbour) clustering was used as the linkage criteria for grouping clusters. We calculated the mean for each of the statements, and mean, standard deviation, and Cronbach's alpha (Cronbach, 1951) for each derived cluster of statements. Statement 7 (Securing direct benefits produced by green and blue spaces is the most significant aspect) was excluded from the analysis on the basis of cluster analysis and statement 1 (Primarily, the connectedness of green spaces at landscape level should be considered) because of the alpha value, cluster analysis and differing content of the statement compared other statements in the cluster (see Appendix 2 Figure 1). 


\section{Rescaled Distance Cluster Combine}

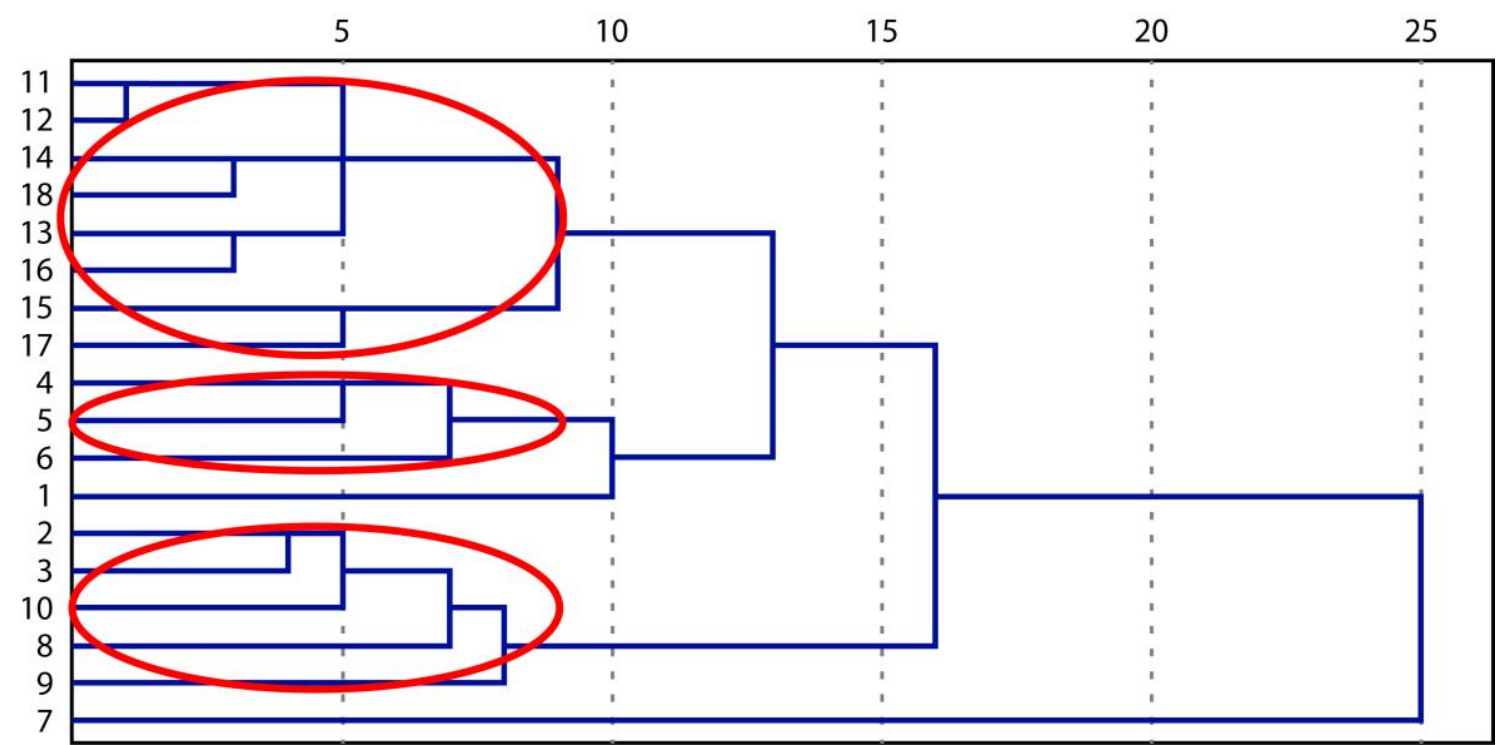

Appendix 2 Figure 1. Dendrogram showing three separated clusters of green infrastructure statements. The Euclidean distance was used as a metric and complete linkage clustering as linkage criteria in hierarchical cluster analysis. The pre-given statements are shown in Table 1 in the article.

Appendix 3. Policy instruments in the questionnaire. The original questions were in Finnish. In all instruments there was an option to answer potential (A) and current (B). The hierarchy of numbering and small case letters was used to compare similar instruments in different countries (not the focus of this study). 
A. How important is [the instrument] potentially for promoting connectivity?

B. How well does it promote connectivity in practice as a part of the current policy mix?

1. National land-use objectives

2. Regional plans

3.a Local master plans

3.b Local detailed plans

3.c Building ordinance

3.d Detailed shore plan

4.a. Overall composition of Biodiversity strategy

4.b. Overall composition of Nature Conservation Act

5. Strict nature reserves

6. National parks

7. Habitat and species protection overall

7.1. Natura 2000 network 
7.2. Protection of species listed in Habitat and Birds Directive

7.3. Other protection of species/habitats

7.3.a Areas protected under conservation programmes of mires, waterfowl habitats, eskers, herb-rich forests, shore areas and old-growth forests and under the act on the protection of rapids

7.3.b Habitats listed in Nature Conservation Act

7.3.c Habitats of special importance listed in Forest Act

7.3.d Species under strict protection and threatened species listed in Nature Conservation Decree

7.3.e Conservation of state-owned land as a part of The Forest Biodiversity Programme METSO

7.3.f Temporary conservation of private land as a part of The Forest Biodiversity Programme METSO

7.3.g Permanent conservation of private land as a part of The Forest Biodiversity Programme METSO

8.a Protected landscapes and sea areas

8.b National urban parks 
8.c Natural monuments

9.a Wilderness areas in Lapland

9.b National hiking areas

10.a Agri-environmental subsidies

10.b Agri-environmental subsidies especially targeted on biodiversity conservation, e.g. subsidy for traditional rural biotopes

10.1. Other funding mechanism, please name it

11. Ecological corridors

12. Buffer zones around conservation areas

13. Environmental impact assessments

14. Overall planning of network of protected areas

15. Green infrastructure

16. Other, please specify 


\section{References}

Cronbach LJ (1951) Coefficient alpha and the internal structure of tests. Psychometrika 16(3): 297-334. 